\title{
Avaliação da balneabilidade das Praias do Farol da Barra e Porto da Barra, Salvador (BA)
}

O termo 'balneabilidade' consiste na qualidade da água destinada à recreação de contato primário. O presente artigo tem por objetivo relatar a condição de balneabilidade das Praias do Farol da Barra e Porto da Barra, localizadas em Salvador (BA), e relatar sobre as possiveis influências. Para a realização deste trabalho além das pesquisas bibliográficas realizadas, foram utilizados como objetos de estudo os dados de monitoramento de Balneabilidade disponibilizados pelo INEMA. De acordo com os resultados apresentados, a Praia do Porto da Barra, própria em $88 \%$ do tempo de monitoramento, e classificada como regular, é a mais indicada para receber atividades que envolvem o contato direto com a água, enquanto a praia do Farol da Barra, monitorada no ponto 02 , apontada como imprópria em $53 \%$ do tempo de monitoramento, foi classificada como péssima para a realização de atividades recreativas. Diante da análise dos resultados estatísticos e das imagens obtidas em visitas ao local, conclui-se que a qualidade da água das praias aqui estudadas sofre interferência da carência de saneamento básico presente no local. Nos pontos estudados foi observado a existência de canais de drenagem operando em condições precárias e de redes clandestinas de esgoto.

Palavras-chave: Monitoramento; Balneabilidade; Praia; Saneamento.

\section{Bathing assessment of Farol da Barra and Porto da Barra beaches, Salvador (BA)}

The term 'bathing' is the quality of water intended for primary contact recreation. This article aims to report the balneability condition of Farol da Barra and Porto da Barra beaches, located in Salvador (BA), and to report on possible influences. For the accomplishment of this work, besides the bibliographical researches carried out, the following data were used as study objects. According to the results presented, Porto da Barra Beach, own in $88 \%$ of the monitoring time, and classified as regular, is the most suitable to receive activities that involve direct contact with water, while Farol da Praia beach. Barra, monitored at point 02 , reported as inappropriate in $53 \%$ of the monitoring time, was rated as very poor for recreational activities. Given the analysis of the statistical results and the images obtained from site visits, it can be concluded that the water quality of the beaches studied here suffers from the lack of basic sanitation present at the site. In the studied points it was observed the existence of drainage channels operating in precarious conditions and clandestine sewage networks.

Keywords: Monitoring; Bathing; Beach; Sanitation

Topic: Engenharia Ambiental

Reviewed anonymously in the process of blind peer
Received: 18/01/2019

Approved: $20 / 02 / 2019$
Luciano da Silva Alves

Centro Universitário Jorge Amado, Brasil http://lattes.cnpq.br/7063630868527586

luciano.eng@outlook.com

Isabela Santos Rabelo

Centro Universitário Jorge Amado, Brasil http://lattes.cnpq.br/7332153294070862 isarabelo172@gmail.com

\section{Referencing this:}

ALVES, L. S.; RABELO, I. S.. Avaliação da balneabilidade das Praias do Farol da Barra e Porto da Barra, Salvador (BA). Natural Resources, v.9, n.1, p.38-46, 2019. DOI: http://doi.org/10.6008/CBPC22379290.2019.001.0005 


\section{INTRODUÇÃO}

Desde os tempos antigos, a busca pela sobrevivência fez com o que homem explorasse os recursos naturais. No entanto, a exploração de forma desordenada tem gerado graves problemas ambientais. Conforme Souza et al. (2015), a poluição está entre as adversidades que mais assolam a zona costeira. A partir desse contexto, a balneabilidade das praias tem sido um dos elementos mais afetados.

De modo geral, o termo balneabilidade é entendido como a qualidade da água destinada a recreação de contato primário, onde há possibilidade de o usuário ingerir quantidades significativas de água. No Brasil, a Resolução CONAMA no 274/2000 é a responsável por dispor os padrões de qualidade. O contato de pessoas a águas contaminadas os colocam à exposição de microrganismos causadores de doenças. De acordo com Berg et al. (2013), estes "microrganismos são responsáveis pela transmissão, aos banhistas, de doenças de veiculação hídrica tais como: gastrenterite, hepatite, cólera, febre tifoide, entre outras".

Em consonância com a saúde, a população tem cada vez mais procurado frequentar balneários que proporcionam boa sanidade. Tendo em vista essa circunstância, praias não balneáveis influenciam diretamente na decadência do turismo local. Segundo Morgan (1999, citado por SOUZA et al., 2015) a qualidade da água para banho, é uma das exigências prioritárias dos turistas.

De acordo com Alves (2018), uma vez que a má qualidade das águas destinadas a recreação mantém relação com a saúde de seus usuários, elaborar pesquisas que informem a sanidade do ambiente, acreditase ser uma maneira de preservar a população de surtos epidêmicos provenientes de águas contaminadas. Em conformidade com a problemática apresentada acima, este artigo tem por objetivo, apresentar a condição de balneabilidade das praias do Farol da Barra e Porto da Barra, localizadas em Salvador - Ba e relatar sobre as possíveis influências.

\section{METODOLOGIA}

\section{Local de estudo}

Para a realização da presente pesquisa, foram escolhidas as praias monitoradas pelo INEMA (Instituto do Meio Ambiente e Recursos Hídricos). Através da COMON (Coordenação de Meio Ambiente e Recursos Hídricos), o órgão monitora 38 pontos de coleta no litoral de Salvador, dos quais três englobam as principais praias utilizadas na orla do Bairro da Barra, são elas: Farol da Barra 01, Farol da Barra 02 e Porto da Barra.

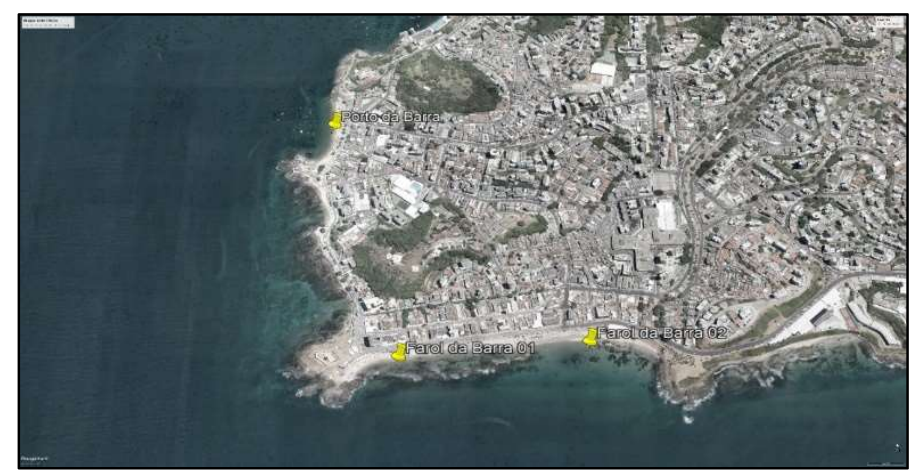

Figura 1: Localização dos Pontos de Coleta. 


\section{Coletas e Análises}

As coletas foram realizadas semanalmente pelo CEPED (Centro de Pesquisas e Desenvolvimento). Anualmente, para cada ponto, são realizadas 52 campanhas, gerando como produto 52 boletins de balneabilidade. Para a realização deste trabalho, foram estudados os laudos e boletins referentes as 52 campanhas realizadas entre 02/01/2017 e 25/12/2017, contemplando o período seco e chuvoso.

A análise microbiológica da água foi realizada através da técnica de tubos múltiplos, onde a contagem de microrganismos ocorreu mediante à utilização do método indireto do Número Mais Provável (NMP). Os procedimentos analíticos realizados pelo CEPED, seguiu as recomendações do Standard Methods for the Examination of Water and Wastewater 21th ed..

O parâmetro microbiológico adotado para determinar a situação de balneabilidade no Estado da Bahia corresponde à quantidade de Escherichia coli. Além desse indicador, estão contidos nos laudos gerados pelo CEPED as informações relacionadas à temperatura da água no momento da coleta, o horário e a data na qual a mesma foi realizada.

Os laudos e boletins adquiridos do INEMA, foram tratados e representados através de abordagens quantitativas e qualitativas. Segundo Fonseca (2002), a utilização conjunta desse tipo de pesquisa permite recolher uma maior quantidade de informações. A análise quantitativa se deu através do propósito de avaliação de balneabilidade das praias localizadas no bairro da Barra, enquanto a qualitativa seguiu os padrões da Resolução CONAMA nํ274/2000 que classifica as águas como Próprias (Excelente, Muito Boa e Satisfatória) e Impróprias.

Quadro 01: Classificação da Balneabilidade.

\begin{tabular}{|c|l|}
\hline Excelente & Máximo de 200 Escherichia coli no conjunto de $80 \%$ amostras. \\
\hline Muito Boa & Máximo de 400 Escherichia coli no conjunto de $80 \%$ amostras. \\
\hline Satisfatória & Máximo de 800 Escherichia coli no conjunto de $80 \%$ amostras. \\
\hline Imprópria & $\begin{array}{l}\text { Acima de } 800 \text { Escherichia coli no conjunto de } 80 \% \text { amostras ou quando o resultado da última amostra for superior a } \\
2000 \text { Escherichia coli. }\end{array}$ \\
\hline
\end{tabular}

Fonte: BRASIL (2000).

\section{RESULTADOS}

A figura 2 apresenta os resultados da condição particular de balneabilidade por categoria: Excelente, Satisfatória, Muito Boa e Imprópria. Nela é possível observar a classificação particular da balneabilidade dos três pontos de monitoramento, sendo dois localizados na praia do Farol da Barra e um no Porto da Barra. A figura 2 foi denominada 'Condição da Balneabilidade no ano de 2017'.

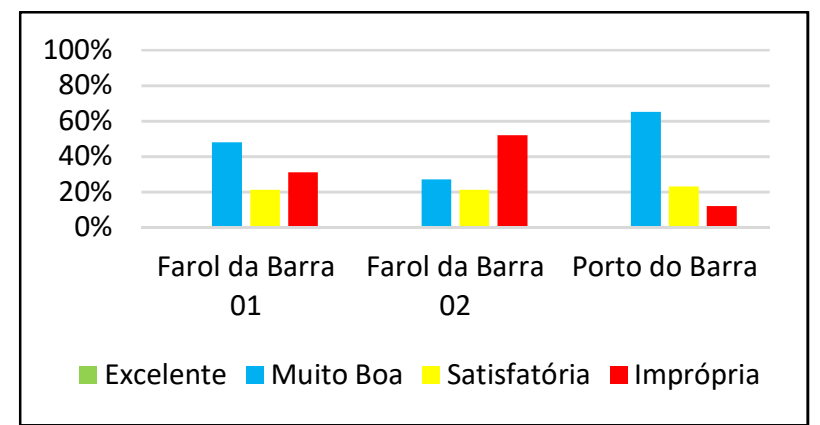

Figura 2: Condição da Balneabilidade no Ano de 2017. 
De acordo com a figura 2, o ponto monitorado no Farol da Barra 01, esteve variando entre as categorias, Muito Boa (48\%), Satisfatória (21\%) e Imprópria (31\%). O segundo ponto de coleta, localizado no Farol da Barra 02, apresentou-se dentro da categoria Muito Boa (27\%), Satisfatória (21\%) e Imprópria (52\%). A Praia do Porto da Barra, teve sua balneabilidade classificada como Muito Boa (65\%), Satisfatória (23\%) e imprópria em apenas $12 \%$ do tempo de monitoramento. Com exceção dos meses de janeiro, abril e setembro, onde foi classificada como Muito Boa, o comportamento da balneabilidade no ponto de monitoramento do Farol da Barra 01 obteve variação mensal entre as categorias (figura 3).

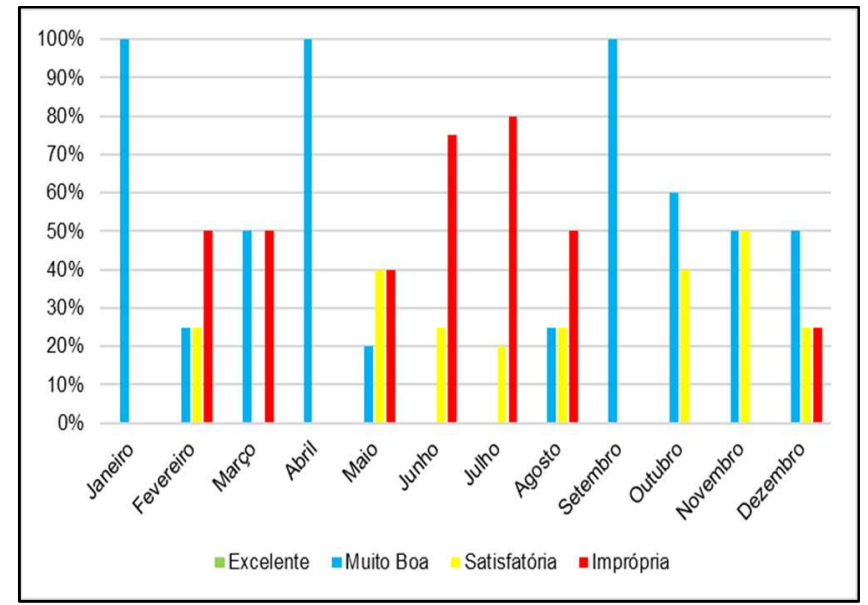

Figura 3: Condição Mensal da Balneabilidade da Praia Do Farol da Barra 01 no ano de 2017.

Durante os meses correspondente a janeiro, abril, setembro e novembro, a balneabilidade foi apontada como própria e $100 \%$ das campanhas realizadas, caracterizando o período como o mais propicio para a prática recreativa. Em contrapartida, os meses de junho e julho a qualidade da água apresentou os piores percentuais, estando classificada com Imprópria em 75 e $80 \%$ das campanhas (figura 3).

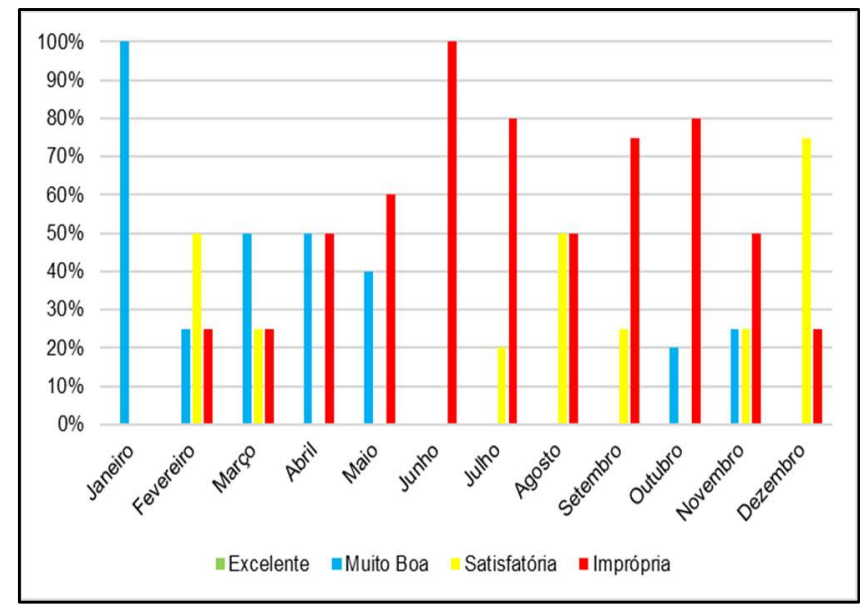

Figura 4: Condição Mensal da Balneabilidade da Praia Do Farol da Barra 02 no ano de 2017.

Avaliando a figura 4, nota-se que a balneabilidade da praia do Farol da Barra 02, apresentou percentuais elevados na categoria Imprópria. Nos meses de maio, junho, julho, setembro e outubro, o ambiente foi classificado como Impróprio em mais de 50\% do tempo de monitoramento. Durante o período de junho, a balneabilidade foi comprometida sistematicamente (100\% Imprópria). 
A Praia do Porto da Barra demonstrou bons percentuais quanto a qualidade da água destinada a recreação. Ressalva os meses de março, abril e dezembro onde a balneabilidade foi apontada como Imprópria em parte das campanhas realizadas, nos demais meses, a praia foi indicada Própria em $100 \%$ do tempo de monitoramento (figura 5).

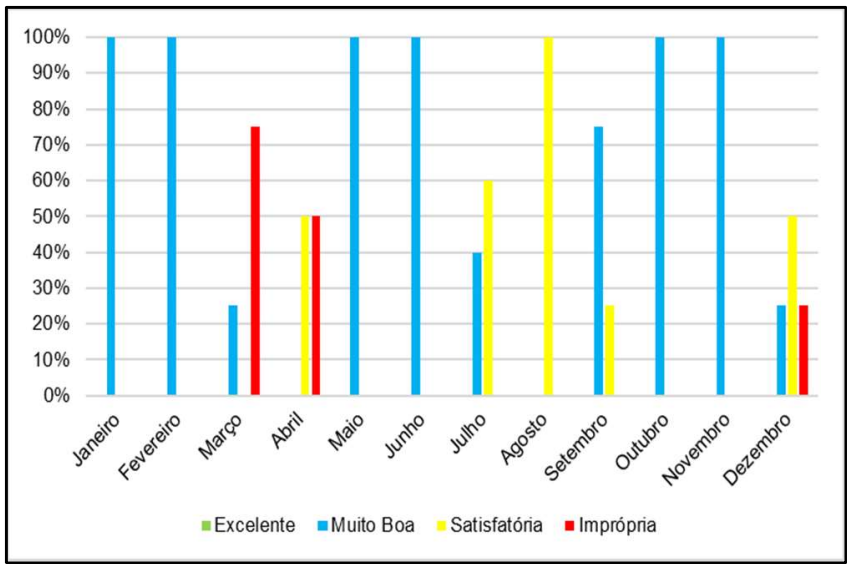

Figura 5: Condição Mensal da Balneabilidade da Praia Do Porto da Barra no ano de 2017.

\section{DISCUSSÃO}

Observa-se, nas figuras 3, 4 e 5, que há períodos onde a balneabilidade demonstrou oscilação de forma não gradual, passando de Muito Boa para Imprópria ou de Imprópria para Muito Boa. Os momentos em que o eventual ocorreu pode ser configurado pela influência significativa de fontes poluidoras, bem como o aumento exponencial da vazão de efluentes descartado no corpo hídrico.

Nas Praias do Farol da Barra 01 e 02, é possível denotar a tendência de piora na qualidade da água nos meses de maio, junho e julho. Baseado na pesquisa de Alves et al. (2018), estima-se que o eventual está associado as precipitações ocorridas no período. Alves et al. (2018) afirma que as chuvas comprometem a balneabilidade do meio, uma vez que este seja destituído de saneamento básico. Isso por que o fenômeno físico é responsável apenas por carrear resíduos, aumentar a vazão dos canais de drenagem, redes de esgotos e rios. Logo, havendo comprometimento de um desses fatores, é provável que haja declínio na balneabilidade.

Tabela 1: Correlação Entre a Balneabilidade e a Precipitação.

\begin{tabular}{|c|c|c|c|c|c|}
\hline \multirow{2}{*}{ Mês } & Farol da Barra 01 & Farol da Barra 02 & Porto da Barra & \multirow{2}{*}{ Precipitação (mm)/Est. Ondina } & \multirow{2}{*}{ Dias de Chuva } \\
\hline & Própria & Própria & Própria & & \\
\hline Janeiro & $100 \%$ & $100 \%$ & $100 \%$ & 22,9 & 12 \\
\hline Fevereiro & $50 \%$ & $75 \%$ & $100 \%$ & 95,8 & 13 \\
\hline Março & $50 \%$ & $75 \%$ & $25 \%$ & 181,1 & 15 \\
\hline Abril & $100 \%$ & $50 \%$ & $50 \%$ & 152 & 20 \\
\hline Maio & $60 \%$ & $40 \%$ & $100 \%$ & 324,3 & 22 \\
\hline Junho & $25 \%$ & $0 \%$ & $100 \%$ & 105,7 & 27 \\
\hline Julho & $20 \%$ & $20 \%$ & $100 \%$ & 218,4 & 28 \\
\hline Agosto & $50 \%$ & $50 \%$ & $100 \%$ & 66,6 & 16 \\
\hline Setembro & $100 \%$ & $25 \%$ & $100 \%$ & 126,1 & 24 \\
\hline Outubro & $100 \%$ & $20 \%$ & $100 \%$ & 74 & 18 \\
\hline Novembro & $100 \%$ & $50 \%$ & $100 \%$ & 77,3 & 9 \\
\hline Dezembro & $75 \%$ & $75 \%$ & $75 \%$ & 83 & 9 \\
\hline \multicolumn{6}{|c|}{ Coeficiente Linear de Pearson } \\
\hline & Praias & Precipitaç & - Própria & Dias de Chuva & \\
\hline
\end{tabular}




\begin{tabular}{|c|c|c|}
\hline Farol da Barra 01 & $-0,38$ & $-0,45$ \\
\hline Farol da Barra 02 & $-0,30$ & $-0,79$ \\
\hline Porto da Barra & $-0,18$ & 17 \\
\hline
\end{tabular}

A tabela 1 expressa a correlação entre balneabilidade e a precipitação (chuva) ocorrida no ano de 2017. Os dados relacionados à precipitação correspondem ao registrado na estação pluviométrica localizada no bairro de Ondina, posta em aproximadamente $1 \mathrm{~km}$ do bairro da Barra. O Coeficiente Linear de Pearson retrata a correlação Linear entre duas variáveis. O valor varia -1 a 1, onde os resultados negativos estão associados a relações inversamente proporcionais (X Cresce; $Y$ Decresce), enquanto que os valores positivos determinam relações de proporção (X Cresce; Y Cresce). Os resultados da tabela 1 retratam para as praias do Farol da Barra 01 e Farol da Barra 02 correlações inversamente proporcionais entre a qualidade da água, volume e frequência da precipitação. Isso significa que, na medida em que as chuvas ocorrem, as praias tendem a ser classificadas como Impróprias.

Os resultados referentes à correlação entre a frequência da precipitação e a qualidade da água das praias do Farol da Barra $01(-0,45)$ e Farol da Barra $02(-0,79)$ elucidam para o referente perfil: ainda que no mês de maio tenha ocorrido o maior volume precipitado $(324,3 \mathrm{~mm})$ nos meses de junho e julho onde os volumes foram menores e as frequências foram superiores (27 e 28 Dias), o decaimento da balneabilidade foi mais expressivo.

Baseado nas correlações obtidas para a praia do Farol da Barra 02, pode-se afirmar que a frequência das precipitações nos meses de agosto, setembro e outubro, justifica a classificação da balneabilidade no período. Na praia do Porto da Barra, os resultados $(-0,18$ e 0,17) encontrados através do Coeficiente Linear de Pearson não determinaram correlações.

Conforme análise das Figuras 6, 7 e 8, pode-se observar que a contaminação das praias do Farol e Porto da Barra são provenientes do lançamento de esgotos sem o devido tratamento. As figuras 3 e 4 retratam canais de drenagem pluvial operando em condições precárias, evidenciando a existência de ligações clandestinas de redes de esgoto. Na figura 8, onde é observada a existência de uma tubulação de PVC direcionada para o corpo hídrico, a ressalva é concreta.

De modo geral a balneabilidade das praias é um fator influenciado pela carência de saneamento básico presente no local. Oliveira et al. (2012) relata que lançamento de esgotos em canais de drenagem e/ou diretamente no corpo hídrico sem o devido tratamento, representa um elemento que contribui diretamente para a contaminação do meio.

Outra vertente a ser detalhada, consiste no fato de que as praias do Farol da Barra e Porto da Barra, estão localizadas numa área com intensa urbanização. $O$ aspecto é tido como uma adversidade para o Meio Ambiente, onde diante da ausência dos serviços de saneamento básico adequado, o ecossistema aquático acaba recebendo volumes de poluentes que favorece a contaminação da água (ALVES, 2018). Nesse sentido, os resultados apontados nas figuras 2, 3, 4 e 5 retratam que, mesmo diante das recentes obras de requalificação da Orla Marítima do Bairro da Barra, as estruturas que envolvem o saneamento básico demonstram ineficiência. 


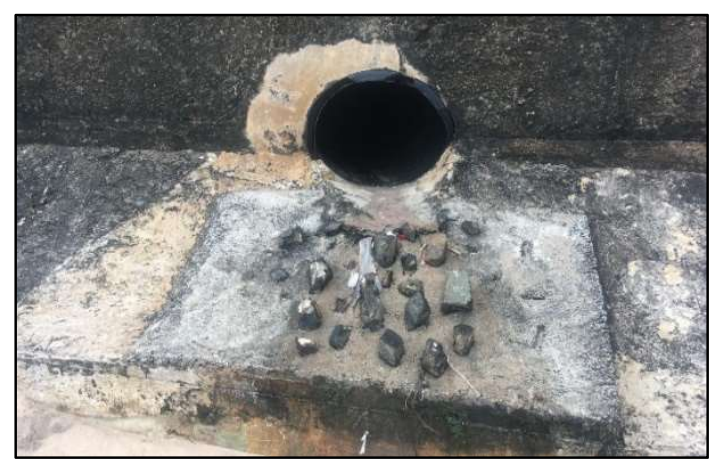

Figura 6: Ponto de coleta 01, Farol da Barra

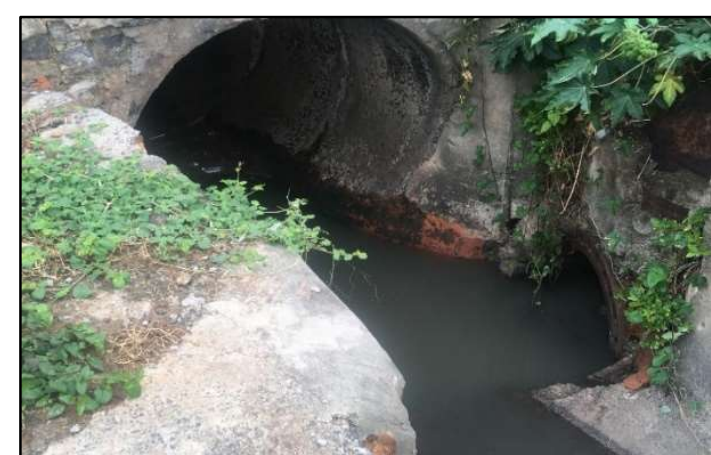

Figura 7: Ponto de Coleta 02, Farol da Barra.

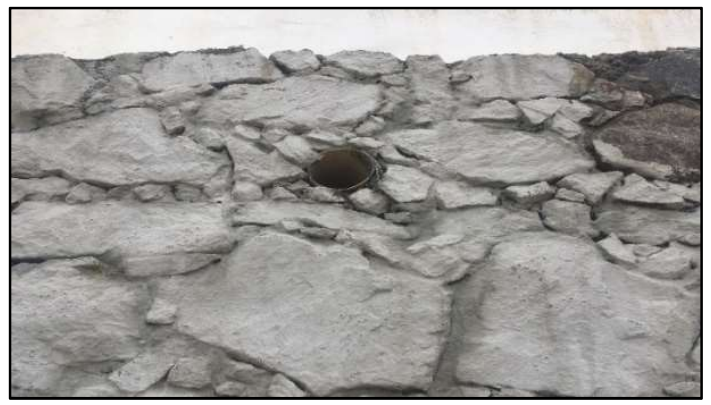

Figura 8: Ponto de Coleta 03, Porto da Barra.

Durante visitas ao local de estudo, pôde-se verificar que no ponto de coleta 02 (Farol da Barra), onde a balneabilidade obtida foi a pior, apresentando-se imprópria em 52\% das campanhas realizadas, há a existência de uma Estação Elevatória de Esgoto da Empresa Baiana de Águas e Saneamento (Embasa). Tal fato exige atenção, pois o problema acontece diante da concessionária responsável pelos serviços de abastecimento de água e esgotamento sanitário do município.

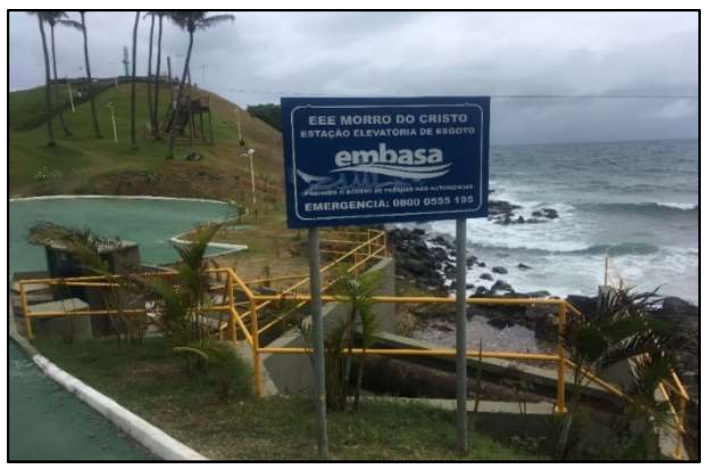

Figura 9: Estação Elevatória de Esgoto no Ponto de Coleta 02, Farol da Barra.

Dado que a balneabilidade das praias aqui estudadas apresentou-se variando ao longo do período de monitoramento, buscou-se apropriar-se do Índice de balneabilidade da Companhia do Estado de São Paulo (Cetesb), para classificar a qualidade da água diante dos percentuais apresentados nas 52 campanhas anuais (Figura 2). A tabela 2 demonstra a distribuição do Índice.

Nesse contexto, visto que a balneabilidade dos pontos monitorados variaram entre as categorias Muito Boa, Satisfatória e Imprópria, conforme a tabela 2, a classificação obtida corresponde à: ruim para o Farol da Barra 01, imprópria em 31\% do tempo de monitoramento (anual) e péssima para o Farol da Barra 02, imprópria em 51\%. Já a praia do Porto do Barra, esta pode ser classificada como regular, pois foi apontada como imprópria em apenas $12 \%$ das campanhas anuais. 
Tabela 2: Índice de Balneabilidade.

\begin{tabular}{|c|c|c|}
\hline Classificação & \multicolumn{2}{|c|}{ CONDIÇÃO ANUAL - PRAIAS } \\
\hline Ótimo & Classificadas como EXCELENTES em 100\% do ano. \\
\hline Boa & Classificadas como PRÓPRIAS em 100\% do ano exceto quando classificadas como EXCELENTES. \\
\hline Regular & Classificadas como IMPRÓPRIAS em até 25\% do ano. \\
\hline Ruim & Classificadas como IMPRÓPRIAS entre 25\% e 50\% do ano. & \\
\hline Péssima & Classificadas como IMPRÓPRIAS em mais de 50\% do ano. & \\
\hline
\end{tabular}

Fonte: Cetesb (2017).

Embora não exista no índice apresentado pela Cetesb, uma correlação com a probabilidade de o usuário adquirir doenças diante das classificações propostas, pode-se afirmar que a praia do Farol da Barra, nos trechos em que é monitorada, não é aconselhável a prática recreativa de contato primário, onde há a possibilidade de o usuário ingerir quantidade significativa de água, ou seja, deve-se evitar o banho, mergulho, natação, e qualquer outra atividade com característica semelhante.

Vale ressaltar que em nenhuma das campanhas, as praias aqui estudadas foram apontadas como excelente. $O$ fato revela a presença de poluição durante todo o tempo de monitoramento (52 campanhas ocorridas em 2017). No período as densidades de Escherichia coli presentes em $80 \%$ ou mais, de um conjunto de cinco amostras foram maiores que 200 por 100 mililitro (BRASIL, 2000).

Segundo Lopes et al. (2015), a busca do contato com o meio natural tem feito com o que a demanda por práticas recreativas que envolvem o contato direto com a água tenha crescido ao longo dos anos. Seguindo esse contexto, é esperado que a sociedade seja informada sobre a sanidade do ambiente. Para Berg et al. (2013), a balneabilidade de uma praia deveria ser um assunto explorado pela mídia, na mesma escala com o que as atrações turísticas são anunciadas.

No Estado da Bahia, quanto ao aspecto de divulgação, o INEMA relatou que os resultados provenientes do monitoramento da balneabilidade no Estado da Bahia, são divulgados toda sexta-feira através de boletins postados nos sites www.inema.ba.gov.br, balneabilidade.inema.ba.gov.br e do aplicativo 'Vai dar Praia', disponível para smartphones com sistema operacional Android.

O boletim consiste num instrumento que tem como objetivo tornar público parte do resultado dos estudos de monitoramento da balneabilidade realizado pelo INEMA. Diante disso são apresentados ao público através contendo a classificação do ambiente de acordo com a Resolução Conama no 274/2000. A Resolução CONAMA no 274/2000 trata apenas dos parâmetros microbiológicos relacionados à qualidade da água. Em análise crítica quanto a legislação em vigor, Oliveira (2017) relata que a classificação da balneabilidade exige análise mais ampla que a proposta. Oliveira (2017) destaca que fatores como a presença de resíduos devem fazer parte do pressuposto de balneabilidade, caso contrário, não seria conveniente considerar um ambiente adequado para uso.

A pesquisa de Alves et al. (2018) reforça a ideia. Nele foi retratado a presença de resíduos da construção civil na praia de Ondina, localizada em Salvador (BA). Logo, mesmo que a qualidade da água fosse apontada como própria, acredita-se que a presença de resíduos na areia da praia possa comprometer a saúde e o bem-estar dos usuários. Levando em consideração que a Resolução CONAMA no274/2000 possui 18 anos 
de existência e desde então não passou por nenhum tipo de revisão, é esperado que numa possível atualização sejam colocadas em pautas, aspectos que visem expandir o conceito de balneabilidade.

\section{CONCLUSÕES}

Esta pesquisa apresentou a condição de Balneabilidade das praias do Farol da Barra e Porto da Barra. De acordo com os resultados apresentados verificou-se que a qualidade da água das praias aqui estudadas obteve variação ao longo do tempo de monitoramento. Seguindo o Índice de Balneabilidade da Cetesb, apenas a praia do Porto da Barra foi apontada como regular para a prática recreativa. Na praia do Farol da Barra, nos trechos onde ocorreu o monitoramento, a balneabilidade foi apontada como ruim (01) e péssima (02). Logo, diante das classificações obtidas, conclui-se que a praia com melhor perfil para a realização de atividades que envolvem o lazer aquático, é a do Porto da Barra.

Em acordo com a análise da imagens, nota-se que o percentuais no qual as praias foram classificadas como imprópria, tem relação com a interferência de canais de drenagem e redes clandestinas de esgoto nos pontos onde a água é coletada. Desse modo, o presente estudo ressalta ainda a importância dos serviços de esgotamento sanitário. Dado que o microrganismo (Eschericha coli) indicador da qualidade da água esclarece o lançamento de esgotos in natura, elaborar ações que contribuam com uma melhor gestão do saneamento básico, representa uma saída para a melhoria da balneabilidade nos pontos aqui estudados.

\section{REFERÊNCIAS}

ALVES, L. S.. Análise da Balneabilidade das Praias do Rio Vermelho em Salvador, Bahia: Paciência, Santana e Buracão. Revista Científica Multidisciplinar Núcleo do Conhecimento, v.3, p.92-102, 2018.

ALVES, L. S.; SANTOS, L. L.; ALVES, C. S.; VIEIRA, C. N. O.; TEIXEIRA, I. C.. Influência da Precipitação na Balneabilidade da Praia de Ondina, no Litoral de Salvador e Sua Relação com o Saneamento Básico. In: CONGRESSO BAIANO DE ENGENHARIA SANITÁRIA E AMBIENTAL, 5. Anais. Juazeiro: UNIVASF, 2018.

BERG, C. H.; GUERCIO, M. J.; ULBRICHT, V. R.. Indicadores de Balneabilidade: A Situação Brasileira e as Recomendações da World Health Organization. International Journal of Knowledge Engineering and Management, Florianópolis, v.2, p.83-101, 2013.

BRASIL. Lei n-274 de $\mathbf{2 9}$ de novembro de $\mathbf{2 0 0 0}$. Dispõe sobre Classificação das águas doces, salobras e salinas essencial à defesa dos níveis de qualidade, avaliados por parâmetros e indicadores específicos, de modo a assegurar as condições de balneabilidade; de forma a assegurar as condições necessárias à recreação de contato primário. Brasília: DOU, 2000 .
CETESB. Companhia Ambiental do Estado de São Paulo. Qualidade das Praias Litorâneas do Estado de São Paulo. São Paulo: CETESB, 2017.

FONSECA, J. J. S.. Metodologia da pesquisa científica. Fortaleza: UESC, 2002.

LOPES, F. A.; SPERLING, E. V.; JUNIOR, A. P. M.. Indicadores de Balneabilidade em Águas Doces no Brasil. Geografias Artigos Cientificos, Belo Horizonte, v.11 p.6-22, 2015.

MORGAN, R.. Preferences and Priorities of Recreational of Beach Users in Wales, UK. Journal of Coastal Research, v.15, n.3, p.653-667, 1999.

OLIVEIRA, K. T. L. L.. De Estação de Cura à Balneabilidade Duvidosa: Análise Ambiental das Praias do Bairro do Rio Vermelho, Salvador, Bahia. Geografia, Ensino \& Pesquisa, Santa Maria, v.21, p.190-205, 2017. DOI: http://doi.org/10.5902/2236499420452

OLIVEIRA, M. A.; MARTINS, L.. Análise Microbiológica da água das praias de Arembepe e Guarajuba, Camaçari - Ba. Candombá, v.8, n.1, p.19-25, 2012.

SOUZA, J. L.; SILVA, I. R.. Avaliação da Qualidade Ambiental da Baía de Todos os Santos. Sociedade \& Natureza, Uberlândia, 2015.

A CBPC - Companhia Brasileira de Produção Científica (CNPJ: 11.221.422/0001-03) detém os direitos materiais desta publicação. Os direitos referem-se à publicação do trabalho em qualquer parte do mundo, incluindo os direitos às renovações, expansões e disseminações da contribuição, bem como outros direitos subsidiários. Todos os trabalhos publicados eletronicamente poderão posteriormente ser publicados em coletâneas impressas sob coordenação da Sustenere Publishing, da Companhia Brasileira de Produção Científica e seus parceiros autorizados. Os (as) autores (as) posteriormente ser publicados em coletâneas impressas sob coordenação da Sustenere Publishing, da Companhia Brasileira de Produção Científica e seus parce
preservam os direitos autorais, mas não têm permissão para a publicação da contribuição em outro meio, impresso ou digital, em português ou em tradução. 